\title{
Reproductive asymmetry and unilateral pregnancy in Chiroptera
}

\author{
W. A. Wimsatt \\ Division of Biological Sciences, Cornell University, Ithaca, New York 14853, U.S.A.
}

\begin{abstract}
Summary. Bats are noteworthy in that anatomical and/or functional asymmetries of the female reproductive organs are far more frequent and profound than recorded for any other mammalian Order, being observed in representatives of all 13 families so far examined. Asymmetry is expressed as a unilateral dominance of an ovary, the uterus, or both. Dextral dominance is most frequent, but cases of sinistral dominance are recorded. In general 6 basic patterns of asymmetry are recognizable. These are briefly described. Physiological factors which may condition expressions of asymmetry in specific cases are discussed, and some avenues for future research are suggested.
\end{abstract}

\section{Introduction}

The female reproductive organs of most birds are profoundly asymmetric, the right ovary being rudimentary and the right oviduct almost totally suppressed (see Witschi, 1935, 1956; Domm, 1939; Taber, 1964). Failure of one ovary to develop fully has also been reported in myxinoids (Cyclostomata), some elasmobranchs and teleost fishes, and a few lizards (Pasteels, 1953; Franchi, Mandl \& Zuckerman, 1962). In mammals it is generally assumed that the female reproductive organs are bilaterally symmetrical, even in monotocous species. Nevertheless, anatomical and functional expressions of asymmetry have now been well documented in monotremes (Pearson, 1949; Mossman \& Duke, 1973), certain marsupials, insectivores, rodents and ungulates (Pearson, 1949; von der Borch, 1963; Funkenstein \& Hellwing, 1977; Ginther, 1967, 1976; Weir, 1971) — and to a most variable and astonishing degree, in Chiroptera (Wimsatt, 1975). The extent to which asymmetric reproductive function characterizes the Chiroptera as a whole is not generally appreciated-hence this brief review. Asymmetry in bats is always associated with the monotocous habit; in the relatively few known polytocous species the female organs are bilaterally symmetrical. The possible selective advantages conveyed by asymmetric reproductive functions in bats can scarcely be guessed at, but it is nevertheless a perplexing question as to why, within this single and ancient group, reproductive asymmetry is so much more prevalent than in any other Order of mammals.

\section{The patterns of asymmetry in Chiroptera}

The available data on female reproductive asymmetries in bats are summarized in Table 1. The information presented is as comprehensive as the existing literature allows, covering species representative of 13 families and numerous genera, but it is not exhaustive. No information exists concerning 4 families of Microchiroptera, and future studies will undoubtedly turn up additional examples and, perhaps, new patterns deviating from those presented here. It will be noted from Table 1 that asymmetry is expressed as a unilateral dominance of right or left ovary, right or left uterus, or both, in various combinations. In bats, unlike birds, dextral asymmetry predominates, 


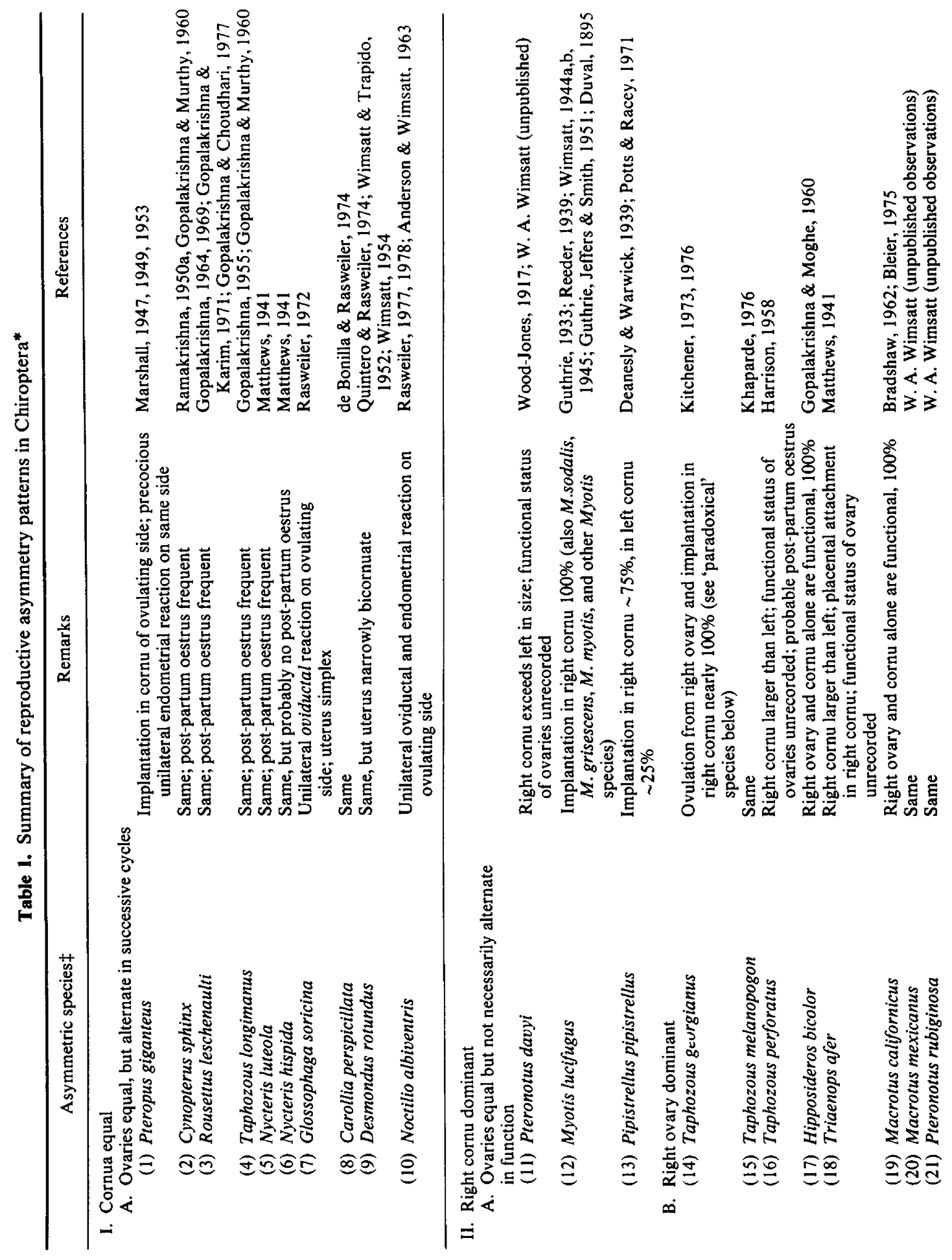



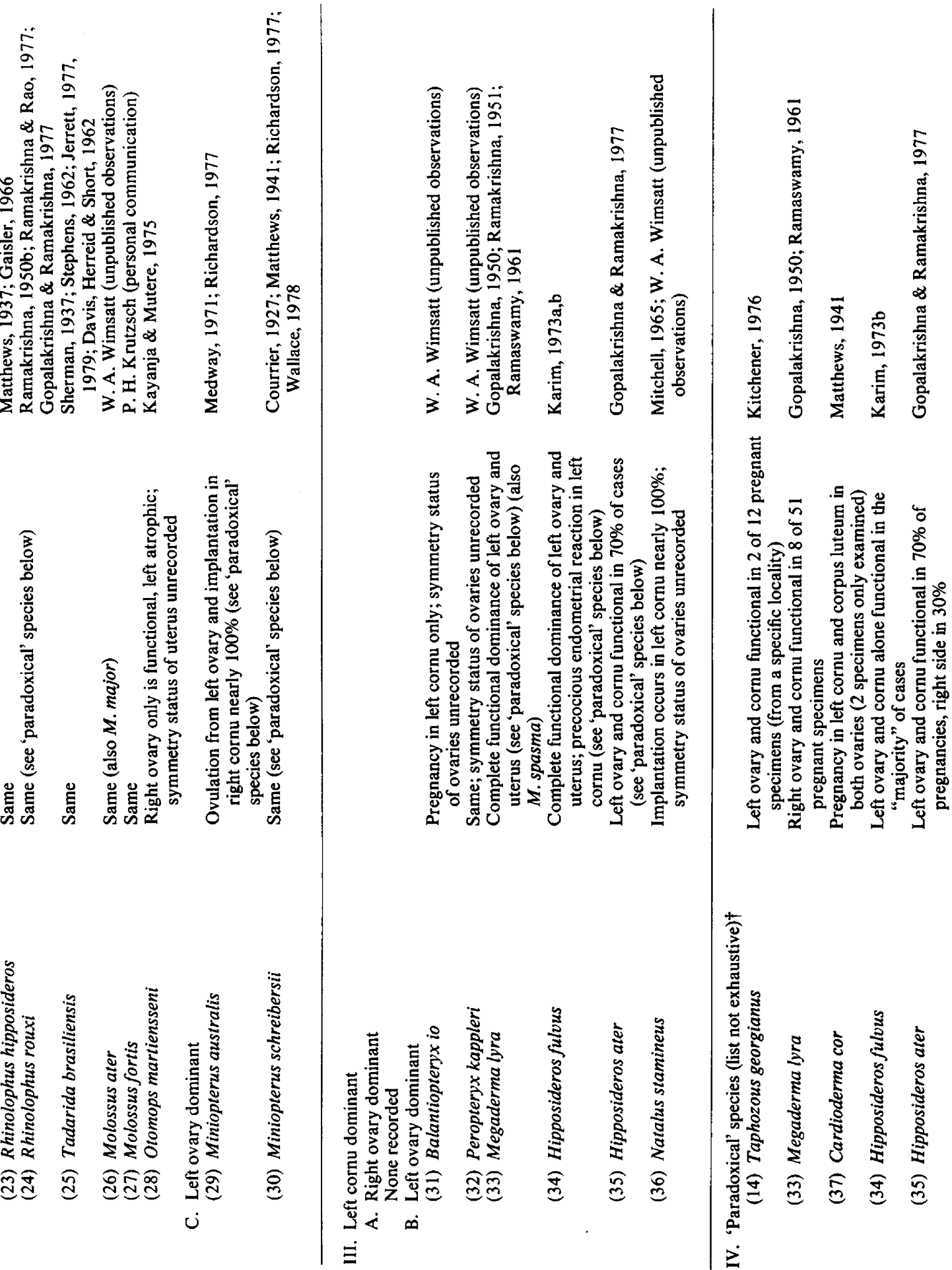


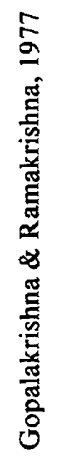

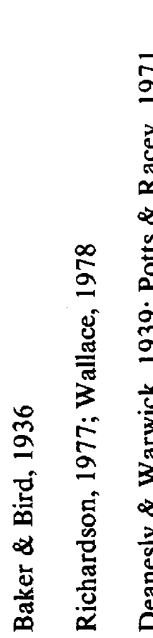

宩

高

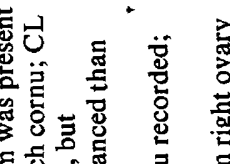

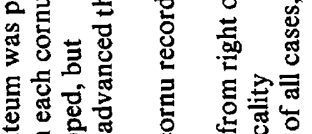

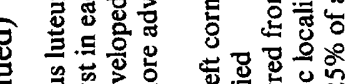

辛

5

s.

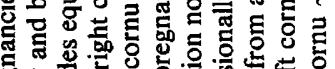

政

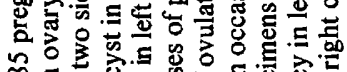

等

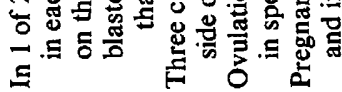

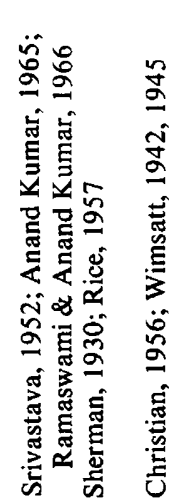

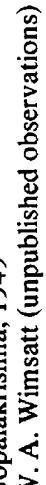

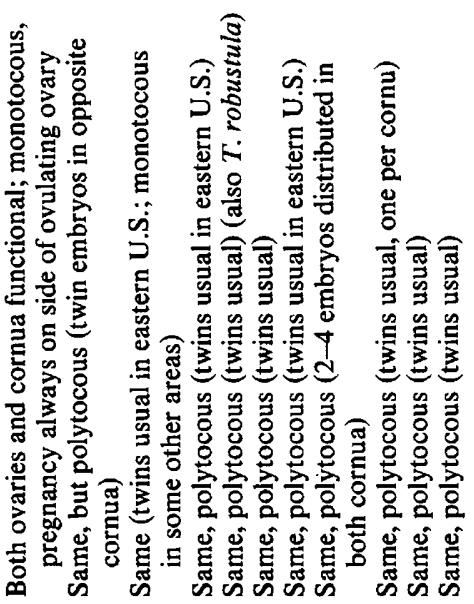

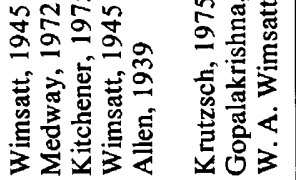

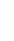

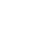

药

William A. Wimsatt 
but there are species showing sinistral dominance, a very few showing contralateral dominance, and 'paradoxical' species in which escapes from the 'normal' pattern of dominance have been reported.

The following six basic patterns of asymmetry in Chiroptera are extrapolated from the data of Table 1, and are also depicted semi-schematically in Text-fig. 1.

\section{Pteropid pattern}

The 'pteropid pattern' (Text-fig. 1b) involves a non-random alternation of ovulations between right and left ovaries in successive cycles. The uterus is septate in the pteropids, and nearly so in the emballonurids displaying this pattern, so that transuterine migration of the ovum is impossible. The corpus luteum of the preceding pregnancy tends to persist until the succeeding oestrus in several species of bats and it has been suggested by several authors that this might condition in some way the alternate functioning of the ovaries (Gopalakrishna, 1969; Quintero \& Rasweiler, 1974; Rasweiler, 1978). An intriguing characteristic of this pattern is the development of a localized progestational reaction of the endometrium at the distal end of the cornu on the side of the ovulating ovary. This reaction occurs after ovulation, during the tubal passage of the ovum, and it marks the presumptive implantation site. The unilateral nature of this reaction implies the existence of a local pathway whereby the endocrine products of the functioning ovary directly influence the ipsilateral cornu. Some, at least, of the species displaying this pattern are seasonally polyoestrous and/or have a post-partum oestrus.

\section{Phyllostomid pattern}

The 'phyllostomid pattern' (Text-figs. Id and 1e) resembles the above in that there is a strong tendency for right and left ovaries to ovulate alternately in successive cycles, but it differs in that a unilateral stimulatory effect of the ovulating ovary is directed upon the ipsilateral oviduct rather than upon the uterus. In the non-phyllostomid, Noctilio, however, the cranial end of the ipsilateral cornu is additionally affected. The oviductal reaction is characterized by fluid distension, and hypertrophy and vacuolation of the lining secretory cells. In Noctilio, and possibly in the phyllostomids cited, vacuolation of the lining epithelium is associated with massive intracellular accumulations of glycogen. Again, this unilateral effect suggests the existence of a local pathway allowing the ovulating ovary to stimulate the ipsilateral oviduct. It should be noted that Glossophaga and Carollia have simplex uteri (Text-fig. 1d), and implantation occurs in the 'intraendometrial segment' of the oviduct on the ovulation side. In Desmodus and Noctilio the uterus is bicornuate and the ovum does enter the uterine cavity; transuterine migration of the ovum is theoretically possible, but implantation normally occurs in the cornu ipsilateral to the ovulating ovary (Text-fig. 1e). In the phyllostomid species the oviductal reaction occurs after ovulation, during tubal transport of the ovum; in Noctilio it is sometimes initiated shortly before ovulation. The oviductal phase of embyronic development is greatly prolonged, the ovum developing to the full blastocyst stage before entering the uterus. This suggests a supportive role of the oviduct in early development which in other mammals is relegated to the uterus. The phyllostomid species cited are polyoestrous, and Desmodus at least may experience a post-partum oestrus (Wimsatt \& Trapido, 1952).

\section{Myotis pattern}

The 'Myotis pattern' (Text-fig. 1c) resembles the preceding two in that ovulation may occur from either ovary with nearly equal frequency, but differs from them in that the ovaries ovulate randomly without evidence of a regular alternation of function. Additionally, the right cornu is 
(a) Migration frequent

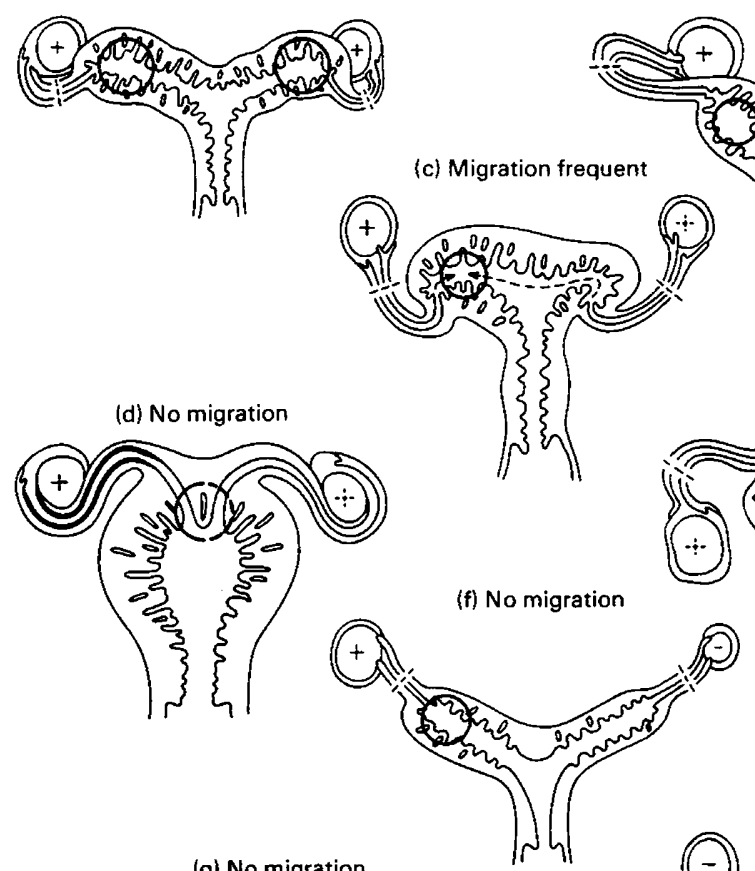

(g) No migration

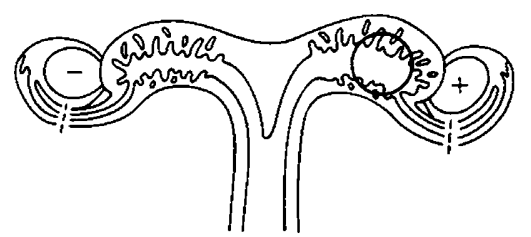

(b) No migration

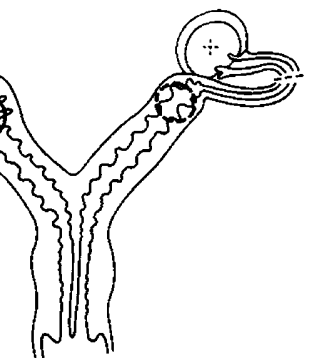

(e) No migration

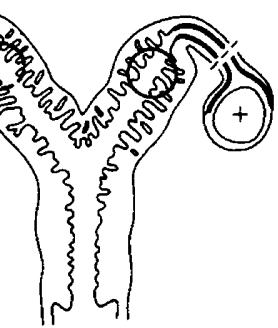

(h) Migration $100 \%$

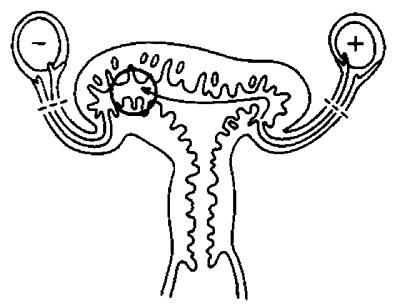

Text-fig. 1. The bold circles within Text-figs 1(a)-1(h) indicate the site of implantation. Dashed circles indicate the site of implantation in a succeeding pregnancy in cases where right and left ovaries function alternately. The $(+)$ and minus $(-)$ signs on the ovaries indicate their competence for ovulation; a dashed 'plus' sign indicates alternating ovulation between ovaries. (a) The 'symmetric pattern', observed only in the few known polytocous species all of which are members of the family Vespertilionidae. (b) The 'pteropid pattern' of functional asymmetry. The enlargement at the apex of the right cornu represents the site of the post-ovulatory unilateral endometrial reaction described in the text. (c) The 'Myotis pattern' of asymmetry. The right cornu is permanently larger than the left and always receives the zygote for implantation. Arrows indicate the path of the ovum depending upon whether it originates from the right or left ovary. (d) and (e) The 'phyllostomid pattern' of functional asymmetry shown by the (d) simplex uterus of Glossophaga and Carollia and (e) bicornuate uterus of Desmodus and Noctilio. The heavier lines in one oviduct in each figure symbolize the unilateral oviductal reaction described in the text. (f) The 'molossid pattern' of asymmetry, characterized by complete dextral dominance of ovary and uterus. The right cornu is slightly larger than the left. (g) The 'Megaderma pattern' of asymmetry, characterized by complete sinistral dominance of ovary and uterus. The left horn is slightly larger than the right. (h) The 'Miniopterus pattern' of asymmetry. This is the only example known of an exclusively contralateral dominance pattern, involving left ovary and right cornu respectively.

dominant over the left in nearly $100 \%$ of cases. Pregnancy occurs only in the right horn, which in parous animals is permanently larger than the left. An ovum originating from the left ovary always migrates to implant in the right cornu. Local effects of the ovulating ovary on the ipsilateral oviduct or uterine horn seem not to be a feature of the 'Myotis pattern' of asymmetry, 
nor would it be expected in animals in which ovulation occurs as often from the contralateral ovary as the one ipsilateral to the functional cornu. The only species known to display this pattern are monoestrous and dwell in temperate latitudes. The tropical species $M$. nigricans appears to be monotocous and monoestrous in central Mexico (Wilson \& Findley, 1970) and in Ecuador (Tamsitt \& Valdivieso, 1963), and could conceivably display the 'Myotis pattern', but at an intermediate latitude (Panama) the species is polyoestrous and may occasionally and perhaps regularly experience a post-partum oestrus (Wilson \& Findley, 1970). Dwyer (1970) claims that $M$. adversus in Queensland is also monotocous and polyoestrous. The functional status of right and left sides of the reproductive tract was not recorded for either of these species. This is unfortunate, for observations on species showing variable reproductive patterns at different latitudes could presumably shed light on the lability of asymmetry patterns in relation to temporal compressions of cyclic breeding behaviour.

\section{Molossid pattern}

The 'molossid pattern' (Text-fig. If) is both the most profound and most widely encountered expression of asymmetry among Chiroptera. It involves a complete dominance of the right ovary and uterus over the left. Typically the left ovary is more or less atrophic, containing few oocytes but abundant interstitial tissue. In non-parous molossids the cornua have most often been described as 'symmetrical', but in Tadarida, at least, the right horn may be slightly larger than the left in parous adults (Davis, Herreid \& Short, 1962). In those rhinolophids, nycterids and hipposiderids known to display the 'molossid pattern' of asymmetry, most authors have noted an anatomical dominance of the right horn over the left in non-pregnant females. Transuterine migration of the ovum from right to left is an extreme rarity in bats of this grouping. Evidence for a preovulatory swelling (pregestational reaction?) of the right cornu in presumably oestrous animals has been presented for Tadarida (Stephens, 1962), and may indicate the existence in this genus of a local unilateral stimulatory pathway between right ovary and uterus. Similar unilateral responses have not been specifically noted, however, in most of the other species listed in this category, but they should be looked for. As far as is known, most of the species are seasonal breeders and monoestrous.

\section{Megaderma pattern}

The 'Megaderma pattern' (Text-fig. $1 \mathrm{~g}$ ) is the converse of the preceding one in that it involves a complete sinistral dominance, the left ovary and cornu being the functional components. The pattern appears less rigid than the 'molossid pattern', however, in that deviations from a wholly sinistral expression of asymmetry are more frequent than are comparable escapes from the dextral dominance of 'molossid pattern' bats (see 'paradoxical' species in Table 1). The emballonurids, Balantiopteryx and Peropteryx, and the natalid, Natalus, are listed in this category because the left cornu is clearly dominant over the right, but functional differences between left and right ovaries have not actually been recorded in them as yet. The observation of Karim (1973a) that in Hipposideros fulvus the ovum which derives from the left ovary implants near the apex of the left cornu at a 'preformed implantation site' provides the only hint that at least some species of this pattern group might possess a local unilateral stimulatory pathway between ovary and uterus. All members of this category appear to be seasonal breeders and monoestrous.

\section{Miniopterus pattern}

The 'Miniopterus pattern' (Text-fig. 1h) characterizes only two species, of the genus Miniopterus. Uniquely, it involves a contralateral dominance pattern in which ovulation occurs 
nearly always from the left ovary and pregnancy occurs almost invariably in the right cornu. In this case (as in the 'Myotis pattern' when ovulation occurs from the left ovary) the ovum always migrates from the left horn to the right for implantation. Functional dominance of the right cornu is obviously inherent and is seldom overridden (see 'paradoxical' species in Table 1). The existence of a local stimulatory pathway between functional ovary and uterus seems most unlikely in this case. Both species of Miniopterus are seasonal breeders and monoestrous at all latitudes (Courrier, 1927; Baker \& Bird, 1936; Dwyer, 1963a, b; Medway, 1971; Richardson, 1977). It should be emphasized that the only real difference between this pattern and the 'Myotis pattern' lies in the intrinsic dominance of the left ovary in miniopterines, for the right cornu is fractionally dominant in both.

For purposes of comparison with the above asymmetry patterns, the 'symmetrical pattern' of the few known polytocous bats, all members of the family Vespertilionidae, is depicted in Textfig. 1(a).

\section{Physiological bases of asymmetry}

The physiological bases of reproductive asymmetry in bats may be as varied as the asymmetry patterns themselves, but since they remain virtually unexplored the following discussion will raise more questions than it will provide answers.

Undoubtedly, the patterns of asymmetry have a genetic basis, but the occasional 'escapes' from the dominance patterns characterizing specific taxa suggest that the genetic predisposition is not necessarily absolute, and can be overriden by regulative influences of a higher order. Genetic effects are probably most directly determinative in those animals in which only one ovary or uterine horn is functional nearly $100 \%$ of the time. For example, the consistent sterility of the left ovary in 'molossid pattern' bats-reflected in its small size, low oocyte population, and inability to respond functionally to removal of the viable right ovary (W. A. Wimsatt, unpublished observations on Molossus sp.; Jerrett, 1977)-may imply an earlier, more basic genetic regulation; this could be true also in respect to the right uterus of bats with the 'Myotis' and 'Miniopterus' patterns which receives the implanting ovum in virtually $100 \%$ of cases irrespective of the side from which the ovum is shed.

Genetic effects, whether strong or weak, are probably most importantly mediated through hormonal action prenatally or postnatally. Since the ovaries and uteri of bats respond similarly to those of other mammals to the familiar gonadotrophins and gonadal steroids (see Wimsatt, 1960 , 1969), contralateral differences in ovarian or uterine functions may imply either a differential sensitivity to the appropriate hormonal stimulus, or a difference in the efficiency of hormone delivery on opposite sides of the tract. It is also conceivable that direct unilateral inhibitory influences of ovary on uterus or vice versa may be involved in some expressions of functional asymmetry, as has been shown in certain other mammals (Ginther, 1976). The developmental morphology and physiology of asymmetry in bats remain unstudied, yet such studies could provide valuable insights concerning the physiological regulation of the various asymmetry patterns. It would be useful to know, for example, whether specific patterns are initiated-in whole or in part-prenatally, before puberty, or at sexual maturity. Presumably those having a prenatal origin would show greater stability than those arising later, be less responsive to higher order regulative influences, and hence less amenable to modification postnatally. The left, non-functional ovary of 'molossid pattern' bats, for example, probably constitutes a prime example of the prenatal establishment of an asymmetry pattern, but this remains to be determined.

While some of the asymmetry patterns of bats seem to be highly consistent and stable, others appear more labile. Examples of the latter include the 'pteropid' and 'phyllostomid' patterns of asymmetry in which a unilateral stimulation of cornu or oviduct occurs around ovulation, and 
changes from side to side as the ovaries alternate in function. Such labile unilateral responses indicate the probable existence of a local mechanism whereby the active ovary directly influences the functional status of the ipsilateral cornu or oviduct. In the absence of information to the contrary it is most logical to assume that the ovarian steroids, oestrogen and/or progesterone, are the principal stimulatory agents involved.

Little is known concerning the mechanisms in bats with reproductive asymmetry whereby local hormonal interactions between ovary and uterus are mediated, but clues as to the types of mechanisms that might be operative, and should be looked for, in bats are to be found in the extensive studies of local mechanisms in certain other mammals. An illustrative example, although it operates in the reverse direction, is the local utero-ovarian pathway involved in the uterus-induced regression of the corpus luteum in cyclic sheep, cattle and guinea-pigs (Ginther, 1974, 1976). A luteolysin (probably prostaglandin F-2 $\alpha$ ) of uterine origin is transmitted to the ovary preferentially by way of a local veno-arterial pathway involving the uterine venous system and the ovarian artery. Text-figure 2, redrawn from Ginther (1976), depicts schematically the special arrangement of these vessels in the sheep. The ovarian artery coils about, and has extensive contact with, the uterine vein. The luteolysin in the uterine veins is transferred, presumably by diffusion through the vessel walls, to the artery, whence it is transported directly to the adjacent ovary. In mammals lacking this intimate veno-arterial arrangement (e.g. horse: Ginther, 1974) it has been shown that there is no local preferential route for direct transfer of substances from uterus to ovary, and the uterine-induced luteolysis must therefore be mediated entirely via the systemic circulation.

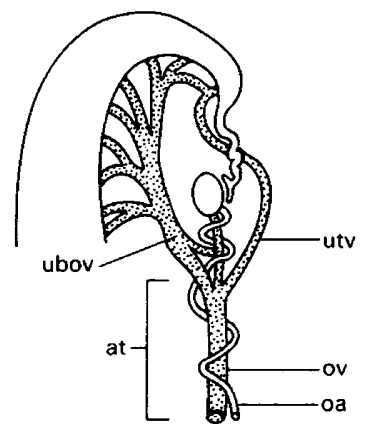

Text-fig. 2. Conceptual scheme of the local veno-arterial pathway in the sheep by which a uterine horn in the absence of an embryo induces regression of the corpus luteum in the ipsilateral ovary (based on Ginther, 1976). at, area of transfer; oa, ovarian artery; ov, ovarian vein; ubov, uterine branch of ovarian vein; utv, uterine tubal vein.

Given this established precedent, it is not illogical to hypothesize the possible existence in 'asymmetric' bats of special vascular arrangements that would enable an active ovary to exert a local, unilateral influence on the ipsilateral uterine horn or oviduct. Such an arrangement could be one that would permit a countercurrent exchange of steroid hormones or other diffusible substances between ovarian or uterine venous and/or lymphatic vessels and arterial branches supplying the ipsilateral cornu and/or oviduct. Present information concerning local mechanisms in asymmetric bats is sparse. Marshall (1953) first observed the close juxtaposition of ovaries and cornual extremities in a giant fruit bat (Pteropus giganteus), and the post-ovulatory development of a localized endometrial reaction in the cranial cornu ipsilateral to the forming corpus luteum. He speculated that ovarian hormones must be passed directly to the cornual extremity via arterial vessels, lymphatics or tissue spaces. Later, Gopalakrishna \& Murthy (1960) examined the utero-ovarian connection in another pteropid (Cynopterus sphinx) and an emballonurid (Taphozous longimanus) and noted a venous connection of a 'possible portal nature' extending between the ovary and the ipsilateral cornual extremity, and cited the possible 


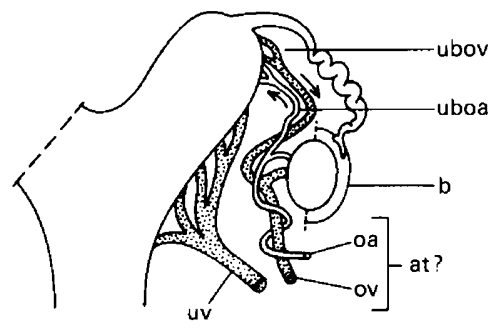

Text-fig. 3. Conceptual scheme of observed and hypothetical components of a possible local veno-arterial pathway in Noctilio by which the ovary could induce a unilateral reaction in the ipsilateral oviduct and cornu (see text). at, area of transfer (hypothetical); b, ovarian bursa; oa, ovarian artery; ov, ovarian vein; uboa, uterine branch of ovarian artery; ubov, uterine branch of ovarian vein.

participation of this vessel in the direct transport of progesterone to the cornu. Finally, Rasweiler (1978) examined the utero-ovarian connections in Noctilio albiventris in serial sections and noted that a small coiled branch of the ovarian artery arising near the ovarian hilus passes via the broad ligament to the cranial extremity of the uterine cornu. This artery is accompanied by a small vein draining the cranial end of the uterine cornu which then joins the vein from the ipsilateral ovary near the hilus. This vascular arrangement is depicted schematically in Text-fig. 3. The drawing is a tentative reconstruction based on Rasweiler's description, down to the level of the ovarian hilus; the relationship of the ovarian artery and vein below this point is my own purely hypothetical construction. Rasweiler did not specifically claim that the ovarian arterial branch and its companion uterine vein were components of a local functional pathway between ovary and uterus, possibly for the reason which follows, but in the context of his discussion he clearly offers it as a possibility. If in fact the local oviductal and uterine reaction of Noctilio is mediated by ovarian hormones from the adjacent ovary via a local vascular pathway it is difficult to understand how the two companion vessels described by Rasweiler could, by themselves, provide an effective countercurrent exchange system for transfer of ovarian hormones to the arterial vessel. The reason is that the uterine vein in question is 'upstream' of the ovarian vein and would not be likely to receive directly the hormonal effluent from the ovary. As Rasweiler points out, the lymphatics draining the ovary could be additional components of a local pathway involving these vessels. It is also conceivable that the ovarian artery, before giving off its uterine branch, could be associated with the ovarian vein in an intimate manner that would facilitate a diffusion of hormones from the latter to the former, as hypothetically depicted in Text-fig. 3, but this is entirely speculative at present.

That local pathways do exist between functional ovary and uterus in bats displaying the more labile types of asymmetry at least, and that they may involve a vascular component, seems highly probable, but detailed studies utilizing more sophisticated techniques than any used to date will be required to demonstrate their presence unequivocally.

\section{Origins of asymmetry}

Space restrictions preclude detailed discussion of possible evolutionary interrelationships of the asymmetry patterns observed in Chiroptera. The prevalence of asymmetry throughout the Order suggests an early origin, but the non-systematic distribution of the various patterns among the taxa creates problems in identifying a probable ancestral type. Did functional asymmetry of the ovaries appear first and somehow influence the development of uterine asymmetry, or did they evolve independently? The inherent dominance of the right cornu in certain bats irrespective of the location of the functional ovary (as in 'Myotis' and 'Miniopterus' patterns) suggests the latter 
to be at least a possibility. The greater prominence of dextral dominance patterns over sinistral dominance, together with the greater completeness of dextral dominance patterns, as seen in the 'molossid' pattern, in comparison to the relatively more flexible sinistral patterns (as exemplified by the 'Megaderma' pattern) in which 'escapes' are more frequent, suggest an earlier origin for dextral dominance. The limited expression of a polytocous habit in bats, being restricted as far as known at present to certain members of a single 'higher' family (Vespertilionidae), suggests that reproductive symmetry may be a relatively recent feature in the evolution of bats. The possibility that present asymmetry patterns may have arisen quite independently within the various ancestral taxa cannot, of course, be excluded. The basic (and unanswered) questions are, what were the selective pressures that led to the evolution of reproductive asymmetry on such a wide scale in Chiroptera in contrast to other mammalian taxa, and what adaptive advantage does (did) asymmetry provide, if any?

\section{References}

Allen, G.M. (1939) Bats. Harvard University Press, Cambridge, Massachusetts.

Anand Kumar, T.C. (1965) Reproduction in the Rattailed bat Rhinopoma kinneari. J. Zool., Lond. 147, $147-155$.

Anderson, J.W. \& Wimsatt, W.A. (1963) Placentation and fetal membranes of the central American noctilionid bat, Noctilio labialis minor. Am. J. Anat. 112 , 181-202.

Baker, J.R. \& Bird, T.F. (1936) The seasons in a tropical rain forest (New Hebrides). Part 4. Insectivorous bats (Vespertilionidae and Rhinolophidae). J. Linn. Soc. Lond. 40, 143-161.

Bleier, W.J. (1975) Early development and implantation in the California leaf-nosed bat, Macrotus californicus. Anat. Rec. 182, 237-253.

Bradshaw, G.V.R. (1962) Reproductive cycle of the California leaf-nosed bat, Macrotus californicus. Science, N.Y. 136, 645-646.

Christian, J.J. (1956) The natural history of a summer aggregation of the big brown bat, Eptesicus fuscus fuscus. Am. Midl. Nat. 55, 66-95.

Courrier, R. (1927) Étude sur le determinisme caracteres sexuels secondaires chez quelques mammifères a activité testiculaire periodique. Archs Biol. 37, 173334.

Davis, R.B., Herreid, C.F., II \& Short, H.L. (1962) Mexican free-tailed bats in Texas. Ecol. Mon. 32, 311-346.

Deanesly, R. \& Warwick, T. (1939) Observations on pregnancy in the common bat (Pipistrellus pipistrellus). Proc. Zool. Soc. Lond. A, 109, 57-60.

de Bonilla, H. \& Rasweiler, J.J., IV (1974) Breeding activity, preimplantation development, and oviduct histology of the short-tailed fruit bat, Carollia, in captivity. Anat. Rec. 179, 385-403.

Domm, L.V. (1939) Modifications in sex and secondary sexual characters in birds. In Sex and Internal Secretions, 2nd edn, pp. 227-327. Eds E. Allen, C. H. Danforth \& E. A. Doisy. Williams \& Wilkins, Baltimore.

Duval, M. (1895) Etudes sur l'embryologie des Cheiroptères. J. Anat. Physiol. 31, 93-160, 427-474.

Dwyer, P.D. (1963a) Reproduction and distribution in Miniopterus (Chiroptera). Aust.J. Sci. 25, 435-436.
Dwyer, P.D. (1963b) The breeding biology of Miniopterus schreibersi blepotis (Temminck) (Chiroptera) in north-eastern New South Wales. Aust. J. Zool. 11, 219-240.

Dwyer, P.D. (1970) Latitude and breeding season in a polyoestrous species of Myotis. J. Mammal. 51, 405-410.

Franchi, L.L., Mandl, A.M. \& Zuckerman, S. (1962) The development of the ovary and the process of oogenesis. In The Ovary, lst edn, vol. 1, pp. 1-88. Ed. S. Zuckerman. Academic Press, New York.

Funkenstein, B. \& Hellwing, S. (1977) The effect of PMSG on ovulation in the shrew, Crocidura russula monacha. Gen. comp. Endocr. 32, 446-453.

Gaisler, J. (1966) Reproduction in the lesser horseshoe bat (Rhinolophus hipposideros hipposideros Bechstein, 1800). Bijdr. Dierk. 36, 45-64.

Ginther, O.J. (1967) Local utero-ovarian relationships. $J$. Anim. Sci. 26, 578-585

Ginther, O.J. (1974) Internal regulation of physiological processes through venoarterial pathways: a review. J. Anim. Sci. 39, 550-564

Ginther, O.J. (1976) Comparative anatomy of uteroovarian vasculature. Vet. Scope 20, 1-17

Gopalakrishna, A. (1949) Studies on the embryology of Microchiroptera, Part III. The histological changes in the genital organs and accessory reproductive structures during the sex-cycle of the vespertilionid bat, Scotophilus wroughtoni (Thomas). Proc. Indian Acad. Sci. 30, 17-46.

Gopalakrishna, A. (1950) Studies on the embryology of Microchiroptera, Part VI. Structure of the placenta in the Indian vampire bat, Lyroderma lyra lyra (Geoffroy). Proc. natn. Inst. Sci. India 16, 93-98.

Gopalakrishna, A. (1955) Observations on the breeding habits and ovarian cycle in the Indian sheath-tailed bat, Taphozous longimanus (Hardwicke). Proc. natn. Inst. Sci. India 21, 29-41.

Gopalakrishna, A. (1964) Post-partum pregnancy in the Indian fruit bat, Rousettus leschenaulti (Desm). Curr. Sci. 33, 558-559.

Gopalakrishna, A. (1969) Unusual persistence of the corpus luteum in the Indian fruit bat, Rousettus leschenaulti (Desmarest). Curr. Sci. 38, 388-389.

Gopalakrishna, A. \& Choudhari, P.M. (1977) Breeding 
habits and associated phenomena in some Indian bats. J. Bombay Nat. Hist. Soc. 74, 1-16.

Gopalakrishna, A. \& Karim, K.B. (1971) Localized progestational endometrial reaction in the uterus of the Indian fruit-bat, Rousettus leschenaulti (Desmerest). Curr. Sci. 40, 490-491.

Gopalakrishna, A. \& Moghe, M.A. (1960) Development of the foetal membranes in the Indian leaf-nosed bat, Hipposideros bicolor pallidus. Z. Anat. EntwMech. 122, 137-149.

Gopalakrishna, A. \& Murthy, K.V.R. (1960) Uteroovarian junction in two species of bats. Bull. Zool. Soc., Coll. Sci. Nagpur 3, 19-22.

Gopalakrishna, A. \& Ramakrishna, P.A. (1977) Some reproductive anomalies in the Indian rufus horse shoe bat, Rhinolophus rouxi (Temminck). Curr. Sci. 46, 767-770.

Guthrie, M.J. (1933) The reproductive cycles of some cave bats. J. Mammal. 14, 199-216.

Guthrie, M.J., Jeffers, K.R. \& Smith, E. (1951) Growth of follicles in the ovaries of the bat Myotis grisescens. J. Morph. 88, 127-144.

Harrison, D.L. (1958) A new race of tomb bat Taphozous perforatus E. Geoffroy, 1818, from northern Nigeria, with some observations on its breeding biology. Durban Mus. Novit. 5, 143-149.

Jerrett, D.P. (1977) Structural-functional differences in the right and left ovaries in the Mexican free-tailed bat, Tadarida brasiliensis mexicana. Anat. Rec. 187 , 615.

Jerrett, D.P. (1979) Female reproductive patterns in nonhibernating bats. J. Reprod. Fert. 56, 369-378.

Karim, K.B. (1973a) Occurrence of a bicornuate vagina in the Indian leaf-nosed bat, Hipposideros fulvus fulvus (Gray). Curr. Sci. 42, 62-63.

Karim, K.B. (1973b) A rare case of twinning in the bat, Hipposideros fulvus fulvus (Gray). Curr. Sci. 42, 823-824.

Kayanja, F.I.B. \& Mutere, F. (1975) The ovary of the insectivorous bat Otomops martiensseni. Anat. Anz. 137, 166-175.

Khaparde, M.S. (1976) Notes on the breeding habits of the Indian sheath-tailed bat, Taphozous melanopogon (Temminck). Mem. Bombay Nat. Hist. Soc. 73, 321-324.

Kitchener, D.J. (1973) Reproduction in the common sheath-tailed bat, Taphozous georgianus (Thomas) (Microchiroptera: Emballonuridae), in western Australia. Aust.J. Zool. 21, 375-389.

Kitchener, D.J. (1975) Reproduction in female Gould's wattled bat, Chalinolobus gouldii (Gray) (Vespertilionidae) in western Australia. Aust. J. Zool. 23, 29-42.

Kitehener, D.J. (1976) Further observations on reproduction in the common sheath-tailed bat, Taphozous georgianus Thomas, 1915 in western Australia, with notes on the gular pouch. Rec. West. Aust. Mus. 4, 335-347.

Krutzsch, P.H. (1975) Reproduction of the canyon bat, Pipistrellus hesperus, in southwestern United States. Am.J. Anat. 143, 163-200.

Marshall, A.J. (1947) The breeding cycle of an equatorial bat (Pteropus giganteus) of Ceylon. Proc. Linn. Soc. Lond. 159, 103-111.
Marshall, A.J. (1949) Pre-gestational changes in the giant fruit bat (Pteropus giganteus), with special reference to an asymmetrical endometrial reaction. Proc. Linn. Soc. Lond. 159, 26-36.

Marshall, A.J. (1953) The unilateral endometrial reaction in the giant fruit-bat (Pteropus giganteus Brünnich). J. Endocr. 9, 42-44.

Matthews, L.H. (1937) The female sexual cycle in the British horse-shoe bats, Rhinolophus ferrumequinum insulanus Barrett-Hamilton and $R$. hipposideros minutus Montagu. Trans. Zool. Soc. Lond. 23, 224-255.

Matthews, L.H. (1941) Notes on the genitalia and reproduction of some African bats. Proc. Zool. Soc. Lond. $B$ 111, 289-346.

Medway, Lord (1971) Observations of social and reproductive biology of the bent-winged bat Miniopterus australis in northern Borneo. J. Zool., Lond. 165 , 261-273.

Medway, Lord (1972) Reproductive cycles of the flatheaded bats Tylonycteris pachypus and $T$. robustula (Chiroptera: Vespertilionidae) in a humid equatorial environment. Zool. J. Linn. Soc. 51, 33-61.

Mitchell, G.C. (1965) A natural history study of the funnel-eared bat Natalus stramineus. Thesis, University of Arizona, Tucson.

Mossman, H.W. \& Duke, K.L. (1973) Comparative Morphology of the Mammalian Ovary. University of Wisconsin Press, Madison.

Pasteels, J. (1953) Contribution a l'ètude du developpment des reptiles. 1. Origine et migration des gonocytes chez deux lacertilians (Mabuia megalura et Chamaeleo bitaeniatus). Archs. Biol. 64, 227-245.

Pearson, O.P. (1949) Reproduction of a south American rodent, the mountain viscacha. Am. J. Anat. 84, $143-171$.

Potts, D.M. \& Racey, P. (1971) A light and electron microscopic study of early development in the bat Pipistrellus pipistrellus. Micron 2, 322-348.

Quintero, F. \& Rasweiler, J.J., IV (1974) Ovulation and early embryonic development in the captive vampire bat, Desmodus rotundus. J. Reprod. Fert. 41, 265273.

Ramakrishna, P.A. (1950a) Reproduction in Cynopterus sphinx (Vahl.). Proc. natn. Inst. Sci. India 16, 362.

Ramakrishna, P.A. (1950b) Some aspects of reproduction in Rhinolophus rouxi (Femm.). Proc. natn. Inst. Sci. India 16, 360-362.

Ramakrishna, P.A. (1951) I. Some aspects of reproduction in the oriental vampires, Lyroderma lyra lyra and Megaderma spasma (Linn). J. Mysore Univ. B 11, 108-118.

Ramakrishna, P.A. \& Rao, K.V.B. (1977) Reproductive adaptations in the Indian rhinolophid bat, Rhinolophus rouxi (Temminck). Curr. Sci. 26, 270271 .

Ramaswami, L.S. \& Anand Kumar, T.C. (1966) Effect of exogenous hormones on the reproductive struc tures of the female bat Rhinopoma during the nonbreeding season. Acta anat. 63, 101-123.

Ramaswamy, K.R. (1961) Studies on the sex-cycle of the Indian vampire bat, Megaderma (Lyroderma) lyra lyra (Geoffroy). Part I. Breeding habits. Proc. natn. Inst. Sci. India, 27, 287-307. 
Rasweiler, J.J., IV (1972) Reproduction in the longtongued bat, Glossophaga soricina. I. Preimplantation development and histology of the oviduct. $J$. Reprod. Fertil. 31, 249-262.

Rasweiler, J.J., IV (1977) Preimplantation development, fate of the zona pellucida, and observations on the glycogen-rich oviduct of the little bulldog bat, Noctilio albiventris. Am. J. Anat. 150, 269-299.

Rasweiler, J.J., IV (1978) Unilateral oviductal and uterine reactions in the little bulldog bat, Noctilio albiventris. Biol. Reprod. 19, 467-492.

Reeder, E.M. (1939) Cytology of the reproductive tract of the female bat, Myotis lucifugus lucifugus. $J$. Morph. 64, 431-463.

Rice, D.W. (1957) Life history and ecology of Myotis austroriparius in Florida. J. Mammal. 38, 15-32.

Richardson, E.G. (1977) The biology and evolution of the reproductive cycle of Miniopterus shreibersii and M. australis (Chiroptera: Vespertilionidae). J. Zool., Lond. 183, 353-375.

Sherman, H.B. (1930) Birth of the young of Myotis austroriparius. J. Mammal. 11, 495-503.

Sherman, H.B. (1937) Breeding habits of the free-tailed bat. J. Mammal. 18, 176-187.

Srivastava, S.C. (1952) Placentation in the mouse-tailed bat, Rhinopoma kinneari (Chiroptera). Proc. zool. Soc. Bengal 5, 105-131.

Stephens, R.J. (1962) Histology and histochemistry of the placenta and fetal membranes of the bat, Tadarida brasiliensis cynocephala (with notes on maintaining pregnant bats in captivity). Am.J. Anat. 111, 259-286.

Taber, E. (1964) Intersexuality in birds. In Sexuality in Vertebrates Including Man, pp. 285-310. Eds C. N. Armstrong \& A. J. Marshall. Academic Press, New York.

Tamsitt, J.R. \& Valdivieso, D. (1963) Condicion reproductora de una colonia Ecuatoriana del murcielago Myotis negro, Myotis nigricans nigricans (Familia Vespertilionidae). Carib. J. Sci. 3, 49-51.

von der Borch, S.M. (1963) Unilateral hormone effect in the marsupial Trichosurus vulpecula. J. Reprod. Fert. 5, 447-449.

Wallace, G.I. (1978) A histological study of the early stages of pregnancy in the Bent-winged bat
(Miniopterus schreibersii) in north-eastern New South Wales, Australia ( $30^{\circ} 27^{\prime}$ S). J. Zool., Lond. 185, 519-537

Weir, B.J. (1971) Some notes on reproduction in the Patagonian Mountain viscacha Lagidium boxi (Mammalia: Rodentia). J. Zool, Lond. 164, 463467.

Wilson, D.E. \& Findley, J.S. (1970) Reproductive cycle of a neotropical insectivorous bat, Myotis nigricans. Nature, Lond. 225, 1155.

Wimsatt, W.A. (1942) Survival of spermatozoa in the female reproductive tract of the bat. Anat. Rec. 83, 299-307.

Wimsatt, W.A. (1944a) Growth of the ovarian follicle and ovulation in Myotis lucifugus lucifugus. Am. J. Anat. 74, 129-173.

Wimsatt, W.A. (1944b) An analysis of implantation in the bat, Myotis lucifugus lucifugus. Am. J. Anat. 74, 355-411.

Wimsatt, W.A. (1945) Notes on breeding behavior, pregnancy and parturition in some vespertilionid bats of the eastern United States. J. Mammal. 26, 23-33.

Wimsatt, W.A. (1954) The fetal membranes and placentation of the tropical American vampire bat Desmodus rotundus murinus. Acta anat. 21, 285341.

Wimsatt, W.A. (1960) Some problems of reproduction in relation to hibernation in bats. Bull. Mus. Comp. Zool., Harvard. 124, 249-267.

Wimsatt, W.A. (1969) Some interrelations of reproduction and hibernation in mammals. Symp. Exp. Biol. 23, 511-549.

Wimsatt, W.A. (1975) Some comparative aspects of implantation. Biol. Reprod. 12, 1-40.

Wimsatt, W.A. \& Trapido, H. (1952) Reproduction and the female reproductive cycle in the tropical American vampire bat, Desmodus rotundus murinus. Am.J. Anat. 91, 415-446.

Witsehi, E. (1935) Origin of asymmetry in the reproductive system of birds. Am. J. Anat. 56, 119-141.

Witschi, E. (1956) Development of Vertebrates. W. B. Saunders. Philadelphia.

Wood-Jones, F. (1917) The genitalia of the Chiroptera. J. Anat. Physiol. 51, 36-60. 